\title{
Systematic review of effects of current transtibial prosthetic socket designs-Part 2: Quantitative outcomes
}

\author{
Mohammad Reza Safari, PhD; ${ }^{1^{*}}$ Margrit Regula Meier, $\mathbf{P h D}{ }^{\mathbf{2}}$ \\ ${ }^{1}$ Department of Orthotics and Prosthetics, University of Social Welfare and Rehabilitation Sciences, Tehran, Iran; \\ ${ }^{2}$ Department for Occupational Therapy, Prosthetics, and Orthotics, Faculty of Health Sciences, Oslo and Akershus \\ University College of Applied Sciences, Oslo, Norway
}

\begin{abstract}
This review is an attempt to untangle the complexity of transtibial prosthetic socket fit and perhaps find some indication of whether a particular prosthetic socket type might be best for a given situation. In addition, we identified knowledge gaps, thus providing direction for possible future research. We followed the PRISMA (Preferred Reporting Items for Systematic Reviews and Meta-Analyses) guidelines, using medical subject headings and standard key words to search for articles in relevant databases. No restrictions were made on study design and type of outcome measure used. From the obtained search results $(n=1,863), 35$ articles were included. The relevant data were entered into a predefined data form that included the Downs and Black risk of bias assessment checklist. This article presents the results from the systematic review of the quantitative outcomes ( $n=27$ articles). Trends indicate that vacuum-assisted suction sockets improve gait symmetry, volume control, and residual limb health more than other socket designs. Hydrostatic sockets seem to create less inconsistent socket fittings, reducing a problem that greatly influences outcome measures. Knowledge gaps exist in the understanding of clinically meaningful changes in socket fit and its effect on biomechanical outcomes. Further, safe and comfortable pressure thresholds under various conditions should be determined through a systematic approach.
\end{abstract}

Key words: amputation, patellar tendon bearing socket, prosthesis, PTB socket, quantitative outcome, socket, total surface bearing socket, transtibial, TSB socket, vacuum-assisted suction socket, VAS socket.

\section{INTRODUCTION}

More than a decade ago, people with lower-limb amputation stated socket fit as being the most important characteristic of a prosthesis [1]. Little seems to have changed to today, because more recently, participants in a study by Klute et al. reported that prosthetic sockets have top priority. Users expressed their wish for an adaptable prosthetic socket and suspension system that responds to residual limb changes, heat, and activity [2].

The subject remains complex and challenging, mostly because a prosthetic socket is the mechanical coupling between the human and the artificial limb. Loads

\footnotetext{
Abbreviations: $\mathrm{ADL}=$ activity of daily living, $\mathrm{DBS}=$ Downs and Black score, $\mathrm{EMG}=$ electromyography, $\mathrm{GRF}=$ ground reaction force, $\mathrm{HS}=$ hydrostatic, $\mathrm{PEQ}=$ Prosthetic Evaluation Questionnaire, $\mathrm{PTB}=$ patellar tendon bearing, $\mathrm{SACH}=$ solid ankle cushion heel, $\mathrm{SC}=$ supracondylar, $\mathrm{SD}=$ standard deviation, TPI $90+=$ time pressure integral when pressure exceeded 90 percent of the maximal load, TSB $=$ total surface bearing, VAS $=$ vacuum-assisted suction.

*Address all correspondence to Mohammad Reza Safari, PhD; Department of Orthotics and Prosthetics, University of Social Welfare and Rehabilitation Sciences, Tehran, Iran 1985713834; +98(0)21-2218-0010; fax: +98(0)21-2218-0049. Email: m.r.safari.k@gmail.com http://dx.doi.org/10.1682/JRRD.2014.08.0184
} 
are transferred from the socket to the lower-limb skeleton via the residual limb soft tissue. Therefore, a successful socket depends on a snug fit, providing a stable socket and residual limb connection without jeopardizing user comfort or increasing experiences of pain and tissue breakdown [3]. However, the residual limb is not physiologically designed to tolerate forces and moments applied by the socket. Poor socket fit can result in excessive interface normal and shear stresses, increasing the possibility of soft tissue breakdown. Poor socket fit can also influence use of the prosthesis as well as a user's walking pattern, increasing the likelihood of other physical complications and disorders [4]. Further, activities of daily living (ADLs) and social participation may also be influenced by a poor socket, decreasing a user's quality of life [4]. Furthermore, the residual limb is subjected to diurnal and long-term volume changes resulting in precarious socket-fit-related issues [5-6]. Prosthetists are therefore faced with the challenge of creating a viable interface between a relatively stiff environment (the prosthetic socket) and a surface-changing environment with various and variable properties (the residual limb). It is thus understandable that the prosthetic socket remains the number one priority for users. Wearing comfort depends to a great extent on socket shape and fit [1,7-8].

For this review, transtibial prosthetic socket designs were categorized into four main groups. These four groups are based on the load transfer mechanisms [1]. The patellar tendon bearing (PTB) socket's load is proportionally transferred to the residual limb based on gait biomechanics and soft tissue "pressure tolerant limits" according to Radcliffe [9]. Radcliffe defined the patellar tendon, anterior medial tibia flare, anterior muscular compartment, and popliteal area as the "pressure tolerant" areas, while the fibular head, anterior tibia crest, and anterior distal tibia were believed to be sensitive regions [2]. The total surface bearing (TSB) socket incorporates elastomeric liner materials, claiming to apply pressure more evenly over the entire residual limb than PTB sockets $[3,10]$. The third socket design includes hydrostatic (HS) sockets, which are based on Pascal's principle of fluid dynamics, created by using a pressure casting medium in combination with an elastomeric liner $[4,11]$. The last is the vacuum-assisted suction (VAS) socket, which creates an elevated negative pressure between liner and socket [12]. The negative pressure is claimed to increase the rate of fluid drawn into the residual limb, minimizing residual limb volume loss [13]. Improved proprioception, walking ability, and residual limb and socket coupling, as well as less pain and lower interface pressure during stance phase, have been reported [1316]. However, a lack of evidence exists to support the absolute indication of effect on user satisfaction, comfort, performance, mobility, and gait for these socket designs [17-24].

This review is an attempt to untangle the complexity of prosthetic socket fit and perhaps find some indication whether a particular prosthetic socket type might be best for a given situation. In order to do so, analysis of results was performed to find out whether a combination of various outcome measures may show trends for the strength of a particular socket type in relation to specific outcome measures. We analyzed current evidence of the effect of available prosthetic socket designs on the combined characteristic of qualitative and quantitative outcomes in persons with a transtibial amputation. The results of our analysis of the qualitative outcomes published in "Systematic review of effects of current transtibial prosthetic socket designs-Part 1: Qualitative outcomes" (p. 491508) indicate that TSB sockets lead to greater activity levels and satisfaction than PTB sockets in active users, those with a traumatic cause of amputation, and younger users. In addition, evidence for VAS and HS sockets is not strong enough yet and further studies are much needed.

This article presents results of the analysis regarding the quantitative outcomes (e.g., gait analysis, interface pressure measurement). Further, it presents the results of studies comparing the cost of prosthetic services with the findings of subjective and/or objective outcome measures and suggests directions for future research in prosthetic socket designs.

\section{METHODS}

For the complete methods used, including eligibility criteria, sources of information and search, study selection, data collection process, and assessing risk of bias in selected studies, please see the "Methods" section in "Systematic review of effects of current transtibial prosthetic socket designs-Part 1: Qualitative outcomes" (p. 493 ) in this issue. For additional information regarding search queries and data collection, see Appendixes 1 and 2 (available online only). 


\section{RESULTS}

A PRISMA (Preferred Reporting Items for Systematic Reviews and Meta-Analyses) flow diagram was created to summarize the study's selection process and reasons for exclusions [25] (see Figure in "Systematic review of effects of current transtibial prosthetic socket designsPart 1: Qualitative outcomes," p. 494).

\section{Study Selection}

For complete details, please see the "Study Selection" section "Systematic review of effects of current transtibial prosthetic socket designs-Part 1: Qualitative outcomes" (p. 493-94). Study selection resulted in 35 articles to be considered for full review, with 27 specifically examining the effects of available socket designs on quantitative outcomes. The results of these 27 articles are presented here.

\section{Study Characteristics}

Tables 1 and 2 present the studies' designs, settings, and corresponding Downs and Black scores (DBSs). Appendix 3 (available online only) presents the summary data for each included study using a PICOS approach (participants, interventions, comparators, outcomes, and study design).

\section{Methods of Studies}

The methodological designs varied considerably across studies (Table 1). The most frequent design was a crossover design $(n=9)$ [27-28,30-33,41-43], followed by five single-subject/case studies [34-35,38-39,44], four randomized crossover trials [13-14,21,29], and three case series [26,46-47]. The remaining studies were repeated-measure design $(n=1)$ [45], randomized controlled trials $(n=2)[22,24]$, cross-sectional design $(n=$ 2) [36-37], and prospective study $(n=1)$ [40] Table 1.

\section{Participants}

A total of 302 adult participants with amputation, with an average age of $42.64 \mathrm{yr}$, participated in the included studies. Studies reporting the sex of participants showed that the majority of participants were male (male: 162 vs female: 37). Twenty-one studies reported the cause of amputation for participants, revealing that the majority of study participants were amputated due to trauma $(n=146)$. The cause of amputation for 50 participants was vascular insufficiency or diabetes, and 84 were amputated due to causes other than trauma, diabetes, or vascular insufficiency.

\section{Intervention}

PTB sockets were analyzed in three studies, two that did not report the type of suspension used and one that employed supracondylar (SC) or cuff suspension.

The TSB socket was used in 12 studies. Two studies used either silicone suction sockets or silicone liners. Ten studies compared the effects of liner material (type or thickness) or the suspension provided by liners (pin lock vs sleeve suspension $[n=2]$ and pin lock vs Seal-In $[n=$ 6]). One study compared PTB and TSB sockets, but the type of suspension used was not reported for either socket.

Four studies compared VAS sockets with TSB sockets - two studies reported liner type for VAS socket (both used urethane). The TSB sockets were used with either urethane, Alpha liner, or gel liner. Four studies used VAS sockets only, but no information was provided for the type of liner tested, except for one study that used a urethane liner for the TSB socket.

HS sockets (IceCast and Icex) were compared with PTB sockets (suspension not reported) in two studies. One study compared an Icex socket and TSB socket with Comfort and Two Color liners.

The adaptation time for the testing sockets varied, usually among studies. Six studies adopted a socket adaptation time of less than $3 \mathrm{mo}$, and in six studies, participants used their study prosthesis for a period of 3 mo or longer. In the remaining studies $(n=5)$, the wearing time was not consistent for participants, i.e., varied from less than 3 mo to 3 mo or longer. Socket adaptation time was not reported in 10 studies.

\section{Outcomes}

Because the type of outcome measures used was not considered to be a study selection criteria, the review identified 14 categories of outcome measures, of which 9 were of quantitative nature. The categories for quantitative outcomes include (1) gait parameters, (2) weight-bearing capability, (3) interface normal and shear stresses, (4) residual limb and socket movement, (5) residual limb volume control, (6) wound healing, (7) energy cost of walking, (8) muscle activity, and (9) time and cost of socket manufacturing. Results of each of these categories are presented later. 
Table 1.

Study designs and settings.

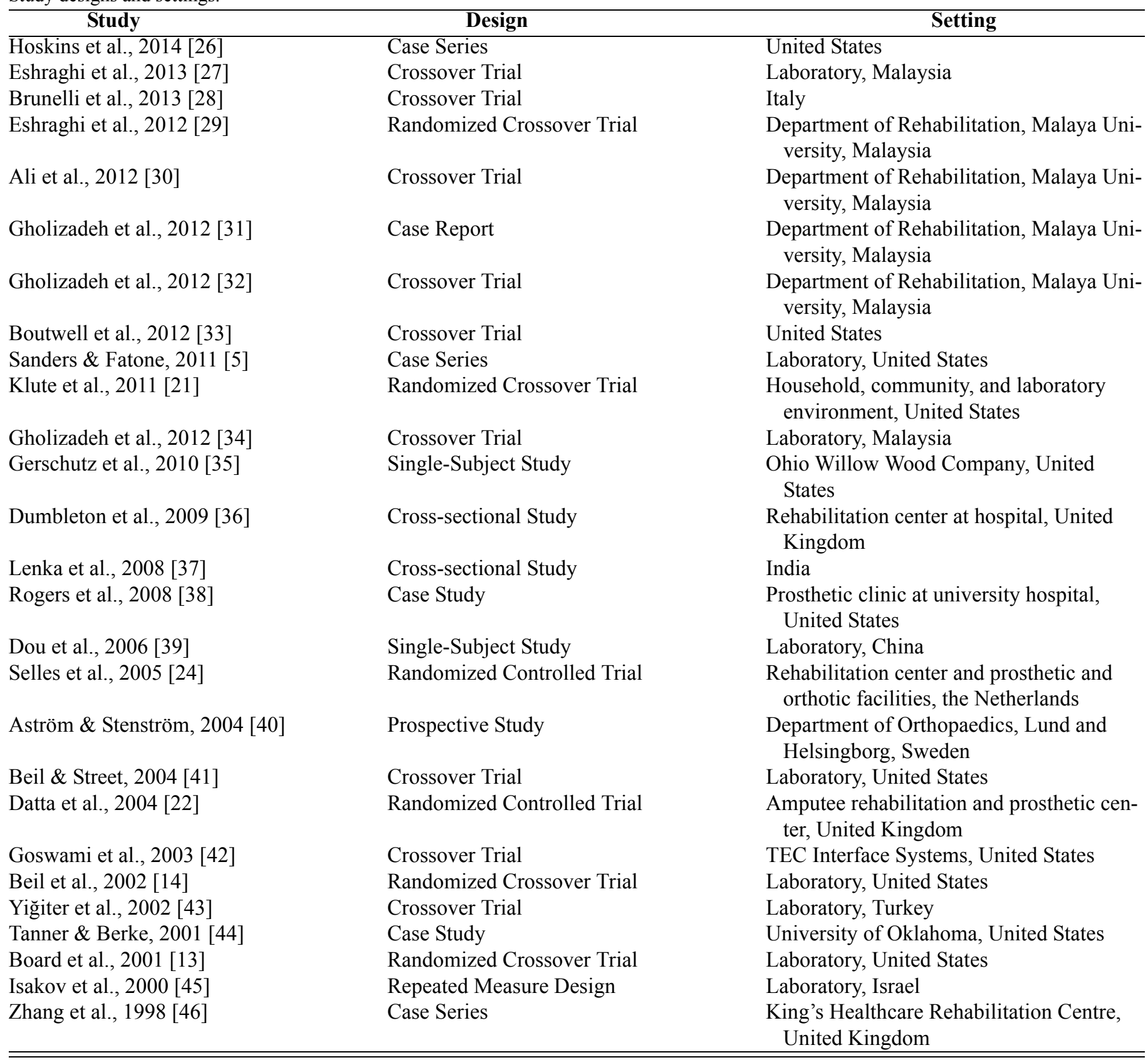

\section{Risk of Bias Within Studies}

The maximum DBS is 32 ; studies with a DBS $\leq 7$ were excluded. For the ease of synthesizing and categorizing the results, studies with a DBS between 7 and 15 were grouped as having weak evidence $(n=9)$, between 16 and 23 as having moderate evidence $(n=16)$, and between 24 and 32 as having robust evidence $(n=2)$ (Table 2).

\section{Syntheses of Results}

A meta-analysis of the results was not possible because the included studies varied too greatly in their methodological design, intervention, participants, and outcome measures. Therefore, a qualitative synthesis of the results was performed. The results are listed in relation to the nine quantitative outcome measure categories identified previously, categorized according to socket 
type and ranked within each section in accordance to their level of evidence.

\section{Gait Parameters}

Eleven studies analyzed the effects of prosthetic socket design on gait parameters, such as walking speed or step symmetry. Out of these studies, three were classified as having weak evidence [37-38,40], six as having moderate evidence $[22,28,33,43,45,48]$, and two as having robust evidence $[13,24]$.

PTB. Moderate evidence-According to a repeatedmeasures design by Isakov et al. (DBS 16), single-limb support time and stance time were longer on the nonamputated side $(0.41$ vs $0.44 \mathrm{~s}$ and 0.71 vs $0.74 \mathrm{~s}$, respectively) in participants wearing PTB sockets with a solid ankle cushion heel $(\mathrm{SACH})$ foot, while swing time (0.44 vs $0.41 \mathrm{~s})$, step time $(0.58$ vs $0.51 \mathrm{~s})$, and step length (0.71 vs $0.69 \mathrm{~m})$ were longer on the prosthetic side [45]. The knee angle at heel strike was larger with the prosthetic limb than with the nonamputated limb $\left(7.5^{\circ}\right.$ vs $\left.4.36^{\circ}\right)$. The maximum swing knee flexion and the knee flexion during loading response and at toe-off were not significantly different between the two legs, but suspension type was not mentioned.

Weak evidence-During walking, stance duration of the sound limb was reported to be longer in participants using PTB sockets and SACH feet compared with nondisabled persons according to a cross-sectional study by Lenka et al (DBS 10) [37]. Younger participants (mean \pm standard deviation [SD] age: $24 \pm 3.8 \mathrm{yr}$ ) walked faster $(1.12 \pm 0.15 \mathrm{~m} / \mathrm{s}$ vs $0.66 \pm 0.14 \mathrm{~m} / \mathrm{s})$, had a higher step symmetry ( $99 \%$ vs $81 \%$ ), and exerted more force to the prosthetic limb at heel strike and late stance (push-off) than older participants (mean \pm SD age: $71 \pm 6 \mathrm{yr}$ ). The difference between younger and older participants was reported to be larger than the difference between the younger and older nondisabled individuals. These larger forces exerted on the nonamputated limb could increase the possibility of knee osteoarthritis in the intact limb.

TSB. Moderate evidence-Researchers investigated the effect of liner thickness and the type of suspension provided by a liner in TSB sockets. Brunelli et al. (DBS 22) reported that people with a TSB socket with sleeve suspension system demonstrated a floor walking speed of $1.72 \pm 0.18 \mathrm{~m} / \mathrm{s}$ [28]. Subjects switched to a TSB socket with hypobaric Seal-In liner and were retested after a familiarization period of $7 \mathrm{wk}$. The floor walking speed was $1.24 \pm 0.10 \mathrm{~m} / \mathrm{s}$, a decrease of 5.5 percent, but this difference was not statistically significant. Comparing a $9 \mathrm{~mm}$-thick liner with a $3 \mathrm{~mm}$-thick version in combination with a TSB socket, Boutwell et al. (DBS 20) reported no significant difference between the two liners in terms of various gait parameters such as walking speed, timing of vertical and fore-aft ground reaction forces (GRFs), loading peak relative to initial contact, stance knee flexion, and pelvic obliquity [33]. Differences, however, were found for the larger magnitude of vertical GRF and the loading peak (percent body weight) during 40 percent of stance phase in the $9 \mathrm{~mm}$-thick liner only $(103.9 \pm 9.7$ vs $106.9 \pm 9.6)$. Boutwell et al. indicated that this could not be attributed to the speed of walking because there was not a significant difference between liners in walking speed. They reasoned that this larger vertical GRF can be a result of decreased sensory input caused by the thicker gel liner and that, therefore, participants may have stepped more forcefully to increase the sensory feedback.

Weak evidence-Aström and Stenström (DBS 15) reported that in participants (mean age: $39.77 \mathrm{yr}$ ) fitted with a new TSB socket with polyurethane liner, comfortable and fast walking speeds increased compared with their previous prosthesis (Icelandic Roll-on Suction Socket $[n=5]$ or ethylene vinyl acetate socket $[n=2]$ ) (mean difference: $0.72 \pm 0.14 \mathrm{~m} / \mathrm{s}$ and $0.75 \pm 0.16 \mathrm{~m} / \mathrm{s}$, respectively) [40]. These differences were, however, not statistically tested. Additionally, the gait symmetry for temporal, stride, and kinematic variables were reported to stay similar irrespective of socket type used.

VAS. Weak evidence - In a case study, Rogers et al. (DBS 11) compared gait parameters of a participant wearing three different VAS sockets: one conventional socket and two with different wall-compliant features over the fibular head and distal tibia [38]. The participant's cadence and walking speed were greatest in the VAS socket with the most compliant features. However, the GRFs were similar for all three sockets.

PTB versus TSB. Moderate evidence-Comparing the PTB and TSB sockets, Yiğiter et al. (DBS 19) showed that step length difference between the amputated side and the contralateral side was significantly smaller in prostheses fitted with a TSB socket (1.1 vs $5.0 \mathrm{~cm})$ [43]. Participants also walked significantly faster (1.23 vs $1.09 \mathrm{~m} / \mathrm{s}$ ) and had a higher cadence while wearing a TSB socket. In addition, the amputated side step length relative to the stride length was closer to normal with a TSB 
Table 2.

Risk of bias within included studies using Downs and Black score (DBS). For description of score items, see Appendix 2 (available online only).

\begin{tabular}{|c|c|c|c|c|c|c|c|c|c|c|c|c|c|c|}
\hline & \multicolumn{11}{|c|}{ Reporting } & \multicolumn{3}{|c|}{$\begin{array}{l}\text { External } \\
\text { Validity }\end{array}$} \\
\hline & $\overline{\mathbf{R} 1}$ & $\mathbf{R 2}$ & $\mathbf{R 3}$ & R4 & $\mathbf{R 5}$ & R6 & $\mathbf{R 7}$ & R8 & R9 & R10 & SS & $\overline{\text { EV1 }}$ & EV2 & EV3 \\
\hline Hoskins et al., 2014 [26] & 1 & 1 & 1 & 1 & 0 & 1 & 0 & 0 & 1 & 0 & 6 & 0 & 0 & 1 \\
\hline Eshraghi et al., 2013 [27] & 1 & 1 & 1 & 1 & 1 & 1 & 0 & 0 & 0 & 1 & 7 & 0 & 0 & 0 \\
\hline Brunelli et al., 2013 [28] & 1 & 1 & 1 & 1 & 1 & 1 & 1 & 1 & 1 & 1 & 10 & 0 & 0 & 0 \\
\hline Eshraghi et al., 2012 [29] & 1 & 1 & 1 & 1 & 1 & 1 & 1 & 1 & 1 & 1 & 10 & 0 & 0 & 0 \\
\hline Ali et al., 2012 [30] & 1 & 1 & 1 & 1 & 1 & 1 & 1 & 1 & 1 & 1 & 10 & 0 & 0 & 0 \\
\hline Gholizadeh et al., 2012 [31] & 1 & 0 & 1 & 1 & 0 & 1 & 0 & 0 & 0 & 0 & 4 & 0 & 0 & 1 \\
\hline Gholizadeh et al., 2012 [32] & 1 & 1 & 1 & 1 & 1 & 1 & 1 & 1 & 1 & 1 & 10 & 0 & 0 & 0 \\
\hline Boutwell et al., 2012 [33] & 1 & 1 & 1 & 1 & 1 & 1 & 1 & 1 & 1 & 1 & 10 & 0 & 0 & 1 \\
\hline Sanders \& Fatone, 2011 [5] & 1 & 1 & 1 & 1 & 1 & 1 & 0 & 1 & 1 & 0 & 8 & 0 & 0 & 0 \\
\hline Klute et al., 2011 [21] & 1 & 1 & 1 & 1 & 1 & 1 & 1 & 1 & 1 & 1 & 10 & 1 & 0 & 1 \\
\hline Gholizadeh et al., 2012 [34] & 1 & 1 & 1 & 1 & 1 & 1 & 1 & 0 & 1 & 1 & 9 & 0 & 0 & 0 \\
\hline Gerschutz et al., 2010 [35] & 1 & 1 & 0 & 1 & 1 & 1 & 0 & 1 & 1 & 0 & 7 & 0 & 0 & 0 \\
\hline Dumbleton et al., 2009 [36] & 1 & 1 & 1 & 1 & 1 & 1 & 1 & 1 & 1 & 1 & 10 & 0 & 0 & 1 \\
\hline Lenka et al., 2008 [37] & 1 & 1 & 0 & 0 & 0 & 1 & 0 & 0 & 1 & 0 & 4 & 0 & 0 & 1 \\
\hline Rogers et al., 2008 [38] & 1 & 1 & 1 & 1 & 1 & 0 & 0 & 1 & 1 & 0 & 7 & 0 & 0 & 0 \\
\hline Dou et al., 2006 [39] & 1 & 1 & 1 & 1 & 0 & 1 & 0 & 0 & 0 & 0 & 5 & 0 & 0 & 1 \\
\hline Selles et al., 2005 [24] & 1 & 1 & 1 & 1 & 1 & 1 & 1 & 1 & 1 & 1 & 10 & 0 & 0 & 1 \\
\hline Aström \& Stenström, 2004 [40] & 1 & 1 & 1 & 0 & 0 & 0 & 0 & 1 & 1 & 0 & 5 & 1 & 1 & 1 \\
\hline Beil \& Street, 2004 [41] & 1 & 1 & 1 & 1 & 1 & 1 & 1 & 1 & 1 & 1 & 10 & 0 & 0 & 0 \\
\hline Datta et al., 2004 [22] & 1 & 1 & 1 & 1 & 1 & 1 & 1 & 0 & 1 & 1 & 9 & 0 & 0 & 1 \\
\hline Goswami et al., 2003 [42] & 1 & 1 & 1 & 1 & 1 & 1 & 0 & 1 & 1 & 0 & 8 & 0 & 0 & 1 \\
\hline Beil et al., 2002 [14] & 1 & 1 & 1 & 1 & 1 & 1 & 1 & 0 & 1 & 1 & 9 & 0 & 0 & 0 \\
\hline Yiğiter et al., 2002 [43] & 1 & 1 & 1 & 1 & 1 & 1 & 1 & 0 & 1 & 0 & 8 & 0 & 0 & 0 \\
\hline Tanner \& Berke, 2001 [44] & 1 & 1 & 1 & 1 & 1 & 1 & 0 & 0 & 1 & 0 & 7 & 0 & 0 & 1 \\
\hline Board et al., 2001 [13] & 1 & 1 & 1 & 1 & 1 & 1 & 1 & 0 & 1 & 1 & 9 & 0 & 0 & 1 \\
\hline Isakov et al., 2000 [45] & 1 & 1 & 1 & 0 & 1 & 1 & 1 & 0 & 1 & 1 & 8 & 0 & 0 & 0 \\
\hline Zhang et al., 1998 [46] & 1 & 1 & 1 & 1 & 1 & 1 & 1 & 1 & 1 & 0 & 9 & 0 & 0 & 1 \\
\hline
\end{tabular}

socket. However, the type of liner or the suspension mechanism used was not reported for either socket type.

PTB versus HS. Moderate evidence-A randomized control trial carried out by Datta et al. (DBS 23) showed no significant differences between PTB socket and Icex HS socket in any measured gait parameters or symmetry indexes [22]. Stride length, cadence, walking speed, temporal symmetry, spatial symmetry, force symmetry, knee maximum flexion during stance and swing, and knee moments were all similar regardless of whether participants wore a PTB socket or an Icex HS socket.
TSB versus VAS. Robust evidence-Based on the results from a randomized crossover trial, Board et al. (DBS 24) reported that, compared with the TSB socket with sleeve suspension, the VAS socket resulted in increased step length symmetry (3.33 and 1.27, respectively) and stance duration symmetry (3.79 and 2.75, respectively) [13]. The authors reasoned that less residual limb pistoning within the VAS socket may be the basis for the observed increase in gait symmetry.

TSB versus HS. Robust evidence-When analyzing the effect of HS Icex sockets versus TSB sockets with pin lock liner, Selles et al. (DBS 25) reported that there were 
Table 2. (cont)

Risk of bias within included studies using Downs and Black score (DBS). For description of score items, see Appendix 2 (available online only).

\section{Internal Validity: Confounding}

(Selection Bias)

\begin{tabular}{|c|c|c|c|c|c|c|c|c|c|c|c|c|c|c|c|c|}
\hline IV1 & IV2 & IV3 & IV4 & IV5 & IV6 & IV7 & $\overline{\text { SS }}$ & SB1 & SB2 & SB3 & SB3 & SB4 & SB5 & SS & & \\
\hline 0 & 0 & 1 & 1 & 0 & 0 & 1 & 3 & 1 & 0 & 0 & 0 & 1 & 1 & 3 & 0 & 13 \\
\hline 0 & 0 & 1 & 1 & 1 & 0 & 1 & 4 & 0 & 0 & 0 & 0 & 1 & 1 & 2 & 4 & 17 \\
\hline 0 & 0 & 1 & 1 & 1 & 0 & 1 & 4 & 1 & 0 & 0 & 0 & 1 & 1 & 3 & 5 & 22 \\
\hline 0 & 0 & 1 & 1 & 1 & 0 & 1 & 4 & 1 & 0 & 0 & 0 & 1 & 1 & 3 & 5 & 22 \\
\hline 0 & 0 & 1 & 1 & 1 & 0 & 1 & 4 & 1 & 0 & 0 & 0 & 1 & 1 & 3 & 5 & 22 \\
\hline 0 & 0 & 1 & 0 & 0 & 1 & 0 & 2 & 0 & 0 & 0 & 0 & 0 & 0 & 0 & 1 & 8 \\
\hline 0 & 0 & 1 & 1 & 1 & 0 & 1 & 4 & 1 & 0 & 0 & 0 & 0 & 1 & 2 & 5 & 21 \\
\hline 0 & 0 & 0 & 1 & 1 & 0 & 1 & 3 & 0 & 0 & 0 & 0 & 1 & 1 & 2 & 4 & 20 \\
\hline 0 & 0 & 1 & 1 & 0 & 0 & 1 & 3 & 0 & 0 & 0 & 0 & 1 & 1 & 2 & 0 & 13 \\
\hline 0 & 0 & 1 & 1 & 1 & 0 & 1 & 4 & 0 & 1 & 1 & 0 & 1 & 0 & 3 & 3 & 22 \\
\hline 0 & 0 & 1 & 1 & 1 & 0 & 0 & 3 & 0 & 0 & 0 & 0 & 1 & 1 & 2 & 5 & 19 \\
\hline 0 & 0 & 1 & 1 & 0 & 1 & 1 & 4 & 0 & 0 & 0 & 0 & 1 & 1 & 2 & 0 & 13 \\
\hline 0 & 0 & 1 & 1 & 1 & 1 & 1 & 5 & 1 & 1 & 0 & 0 & 1 & 1 & 4 & 1 & 21 \\
\hline 0 & 0 & 1 & 0 & 1 & 0 & 0 & 2 & 1 & 0 & 0 & 0 & 0 & 1 & 2 & 1 & 10 \\
\hline 0 & 0 & 1 & 0 & 0 & 1 & 1 & 3 & 0 & 0 & 0 & 0 & 1 & 0 & 1 & 0 & 11 \\
\hline 0 & 0 & 1 & 0 & 0 & 1 & 0 & 2 & 0 & 0 & 0 & 0 & 0 & 0 & 0 & 0 & 8 \\
\hline 0 & 0 & 1 & 1 & 1 & 1 & 1 & 5 & 1 & 1 & 1 & 0 & 1 & 0 & 4 & 5 & 25 \\
\hline 0 & 0 & 1 & 1 & 0 & 1 & 1 & 4 & 1 & 1 & 0 & 0 & 0 & 1 & 3 & 0 & 15 \\
\hline 0 & 0 & 1 & 1 & 1 & 1 & 1 & 5 & 0 & 0 & 0 & 0 & 1 & 1 & 2 & 1 & 18 \\
\hline 0 & 0 & 1 & 1 & 1 & 1 & 1 & 5 & 1 & 1 & 1 & 0 & 1 & 1 & 5 & 3 & 23 \\
\hline 0 & 0 & 1 & 1 & 1 & 0 & 1 & 4 & 0 & 0 & 0 & 0 & 1 & 0 & 1 & 1 & 15 \\
\hline 0 & 0 & 1 & 0 & 1 & 1 & 1 & 4 & 1 & 0 & 1 & 0 & 1 & 1 & 4 & 4 & 21 \\
\hline 0 & 0 & 1 & 0 & 1 & 1 & 1 & 4 & 1 & 0 & 0 & 0 & 1 & 1 & 3 & 4 & 19 \\
\hline 0 & 0 & 1 & 0 & 0 & 0 & 1 & 2 & 0 & 0 & 0 & 0 & 1 & 1 & 2 & 0 & 12 \\
\hline 0 & 0 & 1 & 1 & 1 & 1 & 1 & 5 & 1 & 1 & 1 & 0 & 0 & 1 & 4 & 5 & 24 \\
\hline 0 & 0 & 1 & 1 & 1 & 1 & 0 & 4 & 1 & 1 & 0 & 0 & 1 & 1 & 4 & 0 & 16 \\
\hline 0 & 0 & 1 & 1 & 0 & 0 & 1 & 3 & 1 & 0 & 0 & 0 & 1 & 1 & 3 & 0 & 16 \\
\hline
\end{tabular}

$\mathrm{EV}=$ external validity, $\mathrm{IV}=$ internal validity, $\mathrm{P}=$ power, $\mathrm{R}=$ reporting, $\mathrm{SB}=$ selection bias, $\mathrm{SS}=$ sum score.

no significant differences in any of the kinematic variables measured, such as stride length, stride frequency, walking speed, swing symmetry, and stride length symmetry [24].

\section{Weight-Bearing Capability: PTB versus TSB}

Only one study with a moderate level of evidence reported results on prosthetic socket design and weightbearing capabilities (Yiğiter et al. [43]).

Moderate evidence - Comparing the PTB socket and the TSB socket, Yiğiter et al. (DBS 19) showed improved balance and weight-bearing in participants while they were fitted with a TSB socket [43].

\section{Interface Normal and Shear Stresses}

Nine studies reported normal and shear stresses of the interface. Seven studies were categorized as having moderate evidence $[14,27,30,33,36,41,46]$ and the remaining were grouped as having weak evidence [3839]. None of the studies had robust evidence.

PTB. Moderate evidence-Based on a case series study, Zhang et al. (DBS 16) reported that the average peak pressure in a PTB socket ranged from 25 to $320 \mathrm{kPa}$ 
[46]. The maximum interface pressure during standing was recorded at the popliteal area with values of 125 and $220 \mathrm{kPa}$ during half and full body weight conditions, respectively. Other than the popliteal area, high pressures were also recorded at the medial and lateral tibia regions and at the anteriodistal tibia but not at the patellar tendon. Although the popliteal area had maximum pressure, this area did not have maximum shear stress. The maximum shear stress during standing was measured at the medial tibia and resulted in 33 and $43 \mathrm{kPa}$ during half and full weight-bearing, respectively. The authors indicated that shear stress varied considerably between subjects and measurement areas. During walking, the average peak shear stress ranged from 5 to $61 \mathrm{kPa}$. The walking peak pressure was on average $3.4 \pm 1.5$ times larger than peak pressures obtained during double support standing and 2.4 times larger than during single support. The authors reported that the resultant shear to pressure ratio ranged from 0.1 to 0.6 , averaging 0.3 for the eight sites.

TSB. Moderate evidence-Beil and Street (DBS 18) reported that the average positive interface pressure during stance was not significantly different between TSB sockets with pin lock mechanism (mean: $68.6 \mathrm{kPa}$, range: $15.0-152.1 \mathrm{kPa}$ ) and TSB sockets with suction sleeve suspensions (mean: $66.4 \mathrm{kPa}$, range: $23.1-114.7 \mathrm{kPa}$ ) [41]. A 10 percent undersized urethane liner was used for both sockets while the hard sockets were undersized by 4 percent. During swing phase, the positive pressure impulse and the average positive pressure values were not significantly different in any location measured, but the overall positive pressure impulse value showed a significant difference between pin lock $(3.5 \pm 3.44 \mathrm{kPa})$ and suction sleeve $(0.5 \pm 0.65 \mathrm{kPa})$ suspension systems. In addition, during swing phase, the overall average positive pressure and the negative peak pressure at the distal region of the socket were significantly higher with pin lock suspension than with suction sleeves $(6.7 \pm 5.98 \mathrm{kPa}$ vs $1.1 \pm 1.58 \mathrm{kPa}$ and $-39.5 \pm 14.81 \mathrm{kPa} v \mathrm{vs}-26.1 \pm 7.03 \mathrm{kPa}$, respectively). However, the distal negative pressure impulse values were not different between the two suspensions. The authors reasoned that the higher proximal pressure and distal negative pressure during swing phase could be due to the distal traction of the liner caused by the pin attachment and the resulting increased squeezing effect over the proximal residual limb [41].

According to a crossover trial by Eshraghi et al. (DBS 17), similar results for the Dermo pin lock liner were reported [27]. The authors measured the mean peak interface pressure for TSB sockets with three different liners (Seal-In, pin lock, and distal magnetic lock) during the swing phase using the Tekscan pressure measurement system. The pin lock liner showed a higher interface pressure than the distal magnetic liner at the proximal regions of both the anterior and posterior aspects and the distal region of the anterior aspects of the residual limb. The distal magnetic liner showed the smallest mean peak pressure over these regions (79.26 and $26.01 \mathrm{kPa}$, respectively). At the medial and lateral aspects of the residual limb, there was no significant difference between pin lock and distal magnetic liner. The mean peak pressure for the Seal-In liner was highest at all four sites measured: $119.43,65.29,53.50$, and $52.55 \mathrm{kPa}$ for the anterior, posterior, medial, and lateral locations, respectively.

Ali et al. (DBS 22) also showed that during level walking the mean peak interface pressure at the anterior, posterior, and medial aspects of the residual limb was higher with a Seal-In liner $(84.9,74.5$, and $53.8 \mathrm{kPa}$, respectively) than a pin lock liner $(60.2 .54 .1$, and $50.0 \mathrm{kPa}$, respectively) [30]. Specifically, at the middle regions of the medial, anterior, and posterior aspects of the residual limb; at the proximal region of the anterior aspect; and at the posterior and distal regions of the anterior and medial aspects of the residual limb, the mean peak interface pressure was higher in the Seal-In liner than the pin-lock liner. The authors explained that the higher pressures observed at the middle region of the residual limb in the Seal-In liner could be due to the five seal rings around the liner, which provide an air-tight fit inside the socket.

Boutwell et al. (DBS 20) compared, in a crossover trial, a TSB socket in combination with either a $9 \mathrm{~mm}$ thick or $3 \mathrm{~mm}$-thick liner [33]. They reported a significant reduction in interface pressure over the fibular head $(254 \pm 155 \mathrm{kPa}$ vs $352 \pm 180 \mathrm{kPa}$, respectively) when using the $9 \mathrm{~mm}$ liner. Although not significant, interface pressure at the patellar tendon $(237 \pm 138 \mathrm{kPa}$ vs $177 \pm$ $46 \mathrm{kPa}$, respectively) and the distal anterior tibia (278 \pm $118 \mathrm{kPa}$ vs $254 \pm 54 \mathrm{kPa}$, respectively) was lower for the $3 \mathrm{~mm}$ liner than the $9 \mathrm{~mm}$ liner. Authors stated that there was a 26 percent reduction in interface pressure over bony areas using a thicker liner.

Weak evidence-In a single-subject study by Dou et al. (DBS 8), the interface pressure in a TSB socket with a $6 \mathrm{~mm}$-thick silicone liner was measured using the Novel pliance system [39]. Measurements were taken during walking on level ground, ascending and descending stairs, going up and down slopes, and walking on a non-flat 
road. The mean peak pressures over the patellar tendon, popliteal depression, lateral tibia, medial tibia, and anteriodistal tibia were $166.2,182.7,144.7,76.6$, and $175.9 \mathrm{kPa}$, respectively. During ascending stairs, the mean peak pressure increased at the patellar tendon by 29.84 percent and during walking up a slope by 3.49 percent, while at other regions the mean peak pressure decreased. Maximum pressure occurred at the patellar tendon during ascending stairs with $215.8 \mathrm{kPa}$ followed by $190.0 \mathrm{kPa}$ at the popliteal depression while descending stairs. High pressure occurred at the patellar tendon followed by the popliteal depression and the anteriodistal tibia in most conditions. The authors also calculated the time pressure integral when pressure exceeded 90 percent of the maximal load (TPI 90+). TPI 90+ combines the time the tissue is loaded with the amount of load the tissue is subjected to. During level ground walking, TPI 90+ was $482.60 \mathrm{kPa}$ for the patellar tendon; $321.60 \mathrm{kPA}$ for the popliteal depression; 319.10 and $44.10 \mathrm{kPA}$ for the lateral and medial tibia, respectively; and $107.70 \mathrm{kPa}$ for the anteriodistal tibia. During ascending stairs, the TPI 90+ decreased at the patellar tendon, lateral tibia, and anteriodistal tibia while it increased substantially at the medial tibia. The authors concluded that the interface pressure during level ground walking cannot be highly predictive for stair or slope walking.

VAS. Weak evidence - Rogers et al. (DBS 11) compared interface pressure at the fibular head and the distal tibia for three VAS sockets in a case study: one conventional socket and two with different wall-compliant features over the fibular head and the distal tibia [38]. The authors reported that throughout the stance phase the interface pressure over both locations was higher in the conventional VAS than in the sockets with compliant features. The maximum interface pressure at the distal tibia occurred during midstance with $177.8 \mathrm{kPa}$ for the conventional socket, $88.4 \mathrm{kPA}$ for the socket with compliant feature 1 , and $97.9 \mathrm{kPa}$ for the socket with compliant feature 2 (i.e., most compliant). The maximum interface pressure over the fibular head occurred during terminal stance and was $97.4 \mathrm{kPa}$ for the conventional socket and 33.9 and $25.9 \mathrm{kPa}$ for the sockets with compliant features 1 and 2 , respectively.

PTB versus HS. Moderate evidence-In a crosssectional study, Dumbleton et al. (DBS 21) measured the interface pressure for HS IceCast and PTB sockets at various areas on the residual limb during walking [36]. They reported that the peak values during early stance, mid- stance, and late stance at the anterior, medial, and lateral areas of the proximal region as well as the distal posterior region of the residual limb were significantly higher in the HS than the PTB socket, but the results' variability (i.e., SD) was smaller in the HS socket. The authors explained that the smaller SD could indicate a more consistent fitting of the HS sockets than the PTB sockets. Although the PTB socket had lower interface pressure, the pressure gradients were reported to be steeper. According to the authors, this may result in increased shear stress within the soft tissue of the residual limb. The authors pointed out that a uniform pressure distribution of the HS socket could not be confirmed by their results but highlighted instead that the pressure distribution showed a consistent pattern between the two sockets.

TSB versus VAS. Moderate evidence-Based on a randomized crossover trial by Beil et al. (DBS 21), the positive pressure impulse values of sensors located at the middle medial and lateral area, the medial and the lateral locations of the posterior distal area, and the posterior proximal area of the residual limb were smaller during the stance phase when using a VAS socket than a TSB socket with sleeve suspension [14]. Both sockets were undersized by 4 percent, and the same 10 percent undersized urethane liner was used. The overall average peak positive pressure during stance was lower with the VAS socket than the TSB socket with sleeve suspension (80.0 \pm 23.77 vs $83.5 \pm 25.17$, respectively). The same was observed when analyzing the overall peak pressure and the peak pressures from the middle lateral sensor and from the posterior distal lateral sensor; all were significantly smaller in the VAS socket. During swing phase, the negative pressure impulse and the peak and average peak pressure were, however, higher in the VAS socket $(-13.3,-36.3$, and $-26.5 \mathrm{kPa}$, respectively) than the TSB socket $(-10.5,-28.5$, and $-21.5 \mathrm{kPa}$, respectively). The authors explained that the lower positive pressure during stance and higher negative pressure during swing could result in less residual limb volume loss. Moreover, they reasoned that less pistoning within the VAS socket could be a result of the higher negative pressure observed during swing phase. The authors also analyzed the relationship between residual limb shape and negative pressure and reported that the residual limb taper was only moderately correlated $(r=0.43)$ to the negative pressure, where negative pressure was higher in conical shaped residual limbs. 


\section{Residual Limb and Socket Movement}

Twelve studies evaluated residual limb and socket movements. One study was rated as having robust evidence [13], nine as having moderate evidence [21,28$32,43,49-50]$, and two as having weak evidence $[34,44]$

TSB. Moderate evidence-Based on a case series by Hachisuka et al. (DBS 23), pistoning, tightness of socket during walking, and ease of swing were regarded as "good" or "somewhat good" for TSB sockets with laminated silicone liners by more than 75 percent of participants [49]. For more details regarding Hachisuka et al., please see the qualitative outcomes presented in "Systematic review of effects of current transtibial prosthetic socket designs-Part 1: Qualitative outcomes" (p. 491508).

Four crossover trials reported the difference between Seal-In and Dermo pin lock liners. Gholizadeh et al. (DBS 19) [34] and Eshraghi et al. (DBS 22) [29] measured the socket-liner pistoning movement during static standing position while distal traction loads $(30,60$, and $90 \mathrm{~N}$ ) were applied to the prosthetic limb. Both studies used motion analysis systems to measure pistoning. Eshraghi et al. reported that maximum pistoning occurred after adding a $90 \mathrm{~N}$ distal traction load to the prosthesis and stated that the movement of Dermo liners in relation to the socket was significantly larger than with Seal-In liners: $5.8 \pm 0.8 \mathrm{~mm}$ versus $2.8 \pm 0.5 \mathrm{~mm}$, respectively [29]. They reported further that TSB sockets with a distal magnetic liner showed smaller socket-liner movements than the Dermo liner but larger movements than the Seal-In liner. Gholizadeh et al. reported movements of $5 \pm 1.5 \mathrm{~mm}$ for the Dermo liner versus $2 \pm 1 \mathrm{~mm}$ for the Seal-In liner, supporting participant reports of less skin stretch and more security with the Seal-In liner [34]. It was also stated that when distal traction loads were added to the prosthesis, participants felt greater comfort at the distal part of the residual limb with the Seal-In liner. In another study, Gholizadeh et al. (DBS 21) measured the socketliner vertical movement during gait for these two systems, using a motion analysis system for recording movements [32]. Results showed that the maximum displacement was significantly larger for the Dermo liner $(5.4 \pm 0.6 \mathrm{~mm})$ than for the Seal-In liner $(2.5 \pm 0.4 \mathrm{~mm})$. This maximal displacement occurred during initial swing. Furthermore, participants reported more pistoning for a TSB socket with Dermo liner than a TSB socket with Seal-In liner (Prosthetic Evaluation Questionnaire [PEQ] score: 95.75 vs 72.5). Similar results were reported by Ali et al. (DBS 22) [30] and Eshraghi et al. (DBS 22) [29], where participants experienced less pistoning problems and were more satisfied with the suspension of a TSB socket with Seal-In liner than a TSB socket with Dermo liner. The socket rotation problem was not significantly different between the two suspension systems in Ali et al., while participants rated socket rotation to be less of a problem with a TSB socket with Seal-In liner than either a TSB socket with distal magnetic liner or a TSB socket with Dermo liner in Eshraghi et al.

Brunelli et al. (DBS 22) measured the pistoning movement between two different silicone liners and a TSB socket using digital photography methods [28]. The amount of pistoning during non-weight-bearing was significantly different between the TSB socket with Seal-In liner $(3.6 \pm 3.1 \mathrm{~mm})$ and the TSB socket with sleeve suspension $(7.5 \pm 4.7 \mathrm{~mm})$. When a $30 \mathrm{~N}$ axial load was applied, pistoning was larger with the sleeve suspension $(12.4 \pm 5.6 \mathrm{~mm})$ than with the Seal-In liner $(5.6 \pm 3.1 \mathrm{~mm})$.

Weak evidence-Tanner and Berke (DBS 12) measured vertical tibial translation and vertical soft tissue movement for a single participant when wearing a TSB socket with pin lock liner and a TSB socket with neoprene sleeve suspension [44]. Vertical tibia movement between the two different systems was similar: $31 \mathrm{~mm}$ for the pin lock liner and $36 \mathrm{~mm}$ for the neoprene sleeve suspension. However, the pin lock suspension system provided less distal soft tissue movement than the suspension with neoprene sleeve ( $2 \mathrm{~mm}$ vs $20 \mathrm{~mm}$ ).

Gholizadeh et al. (DBS 8) measured the amount of pistoning movement between the socket and the liner in a participant with bilateral amputation when wearing TSB sockets with Seal-In liners and TSB sockets with Dermo liners using digital camera photography [31]. After adding 90 and $60 \mathrm{~N}$ distal traction loads, the authors reported 4 and $2 \mathrm{~mm}$ pistoning with the Dermo liners compared with 2 and $1 \mathrm{~mm}$ pistoning for the Seal-In liners for the same loads.

PTB versus TSB. Moderate evidence-In a crossover trial, Yiğiter et al. (DBS 19) reported the amount of residual limb pistoning during stance and swing phase by measuring the movement of the socket brim in relation to a mark on the prosthetic sock [43]. Their results showed that the socket pistoning was significantly smaller in the TSB socket $(4 \mathrm{~mm})$ than the PTB socket $(16 \mathrm{~mm})$.

Based on a survey by Ali et al. (DBS 18), participants were significantly more satisfied with the suspension of a TSB socket with Seal-In liner (PEQ score: 93.71) than 
either the TSB socket with pin lock liner (PEQ score: 81.72) or PTB socket with Pelite liner (PEQ score: 55.20 ) [50]. For more details regarding Ali et al., please see the qualitative outcomes presented in "Systematic review of effects of current transtibial prosthetic socket designsPart 1: Qualitative outcomes" (p. 491-508).

TSB versus VAS. Robust evidence-In a randomized crossover trial, Board et al. (DBS 24) reported that the axial movement of the liner and tibia in relation to the socket was significantly smaller in a VAS socket than in a TSB socket [13]. Results were obtained by adding loads to a prosthesis simulating normal walking and running. Differences were measured using X-rays. The liner and tibia movement was 1 and $5 \mathrm{~mm}$, respectively, for VAS socket suspension and 33 and $44 \mathrm{~mm}$, respectively, for the TSB socket. The distal tissue elongation (measured as the position of the liner in relation to the tibia) was not shown to be different between the two socket suspension systems.

Moderate evidence-In a randomized crossover trial, Klute et al. (DBS 22) measured the amount of pistoning between the limb and the socket during weight-bearing and non-weight-bearing conditions [21]. The participants were fitted with a VAS socket and a TSB socket with pin lock liner; movement was measured using a motion analysis system. Results show that the TSB socket had significantly larger pistoning $(6 \pm 4 \mathrm{~mm})$ than the VAS socket $(1 \pm 3 \mathrm{~mm})$.

\section{Residual Limb Volume Control}

Five studies reported the effects of VAS and TSB sockets on residual limb volume, from which one study was classified as having robust evidence [13], one as having moderate evidence [21], and three as having weak evidence $[35,42,47]$.

VAS. Weak evidence - In a crossover trial by Goswami et al. (DBS 15), residual limb volume was measured after 18 min of walking using alginate casting and water-weighting techniques [42]. The results were compared with the available volume of the VAS socket $(-78 \mathrm{kPa}$ pressure at the interface) to verify whether the residual limb retained or gained volume in excess of available socket volumes. Three different socket sizes were prepared: undersized $(-15 \%)$, natural sized $(-7 \%)$, and oversized $(+3 \%)$. The results showed that the residual limbs gained more volume in a VAS socket irrespective of socket size. The residual limbs gained the most volume in the oversized socket (11\%). Subjects lost an average of
2 percent of their volume in the undersized socket, although the socket was undersized by 15 percent. In the natural sized socket, residual limbs gained, on average, 5 percent in volume. No pain, discomfort, or reddening of the skin were reported as a result of the volume gain within the residual limb.

TSB versus VAS. Robust evidence-In a randomized crossover trial, Board et al. (DBS 24) measured the residual limb volume before and after $30 \mathrm{~min}$ of treadmill walking (1.34-1.52 $\mathrm{ms}^{-1}$ ) using a casting and water displacement method [13]. The subjects were tested with a VAS socket, with its vacuum level set at $-78 \mathrm{kPa}$, and with a TSB (non-VAS) socket. The authors reported that the residual limb gained an average of 3.7 percent volume in the VAS socket and lost 6.5 percent of its volume in the TSB socket.

Moderate evidence - In a randomized crossover trial, Klute et al. (DBS 22) measured residual limb volume after 3 wk of using a VAS socket (casting at $-68 \mathrm{kPa}$ ) and a TSB socket with pin lock liner [21]. They used an optical scanner to determine volume changes. The residual limbs were scanned twice: before and after walking on a treadmill for $30 \mathrm{~min}$ at a comfortable walking speed. There were no changes in residual limb volume before $(0.72 \pm 0.12 \mathrm{~L})$ and after $(0.72 \pm 0.12 \mathrm{~L})$ treadmill walking using the VAS socket. The residual limb volume also remained unchanged after using the TSB socket with pin lock liner $(0.69 \pm 0.14 \mathrm{~L}$ and $0.68 \pm 0.13 \mathrm{~L}$ for pre and post walking, respectively, corresponding with a $0.6 \%$ decrease). The results also show that doffing the prosthesis resulted in residual limb volume increase. Postdoffing residual limb volume increased by 4.5 percent for the TSB socket after walking, 4.1 percent for the VAS socket before walking, and 6.3 percent for the VAS socket after walking. Fifty percent of volume change took place in less than 2 min after doffing the prosthesis, and 95 percent of volume increase occurred within less than $8 \mathrm{~min}$. The authors stated that neither walking nor socket type had a significant effect on residual limb volume changes.

Weak evidence - In a single-subject study by Gerschutz et al. (DBS 13), the effect of a VAS socket with two different negative pressures $(-33.86$ and $-50.79 \mathrm{kPa})$ were compared together with a zero negative pressure socket, i.e., a TSB suction socket [35]. Postdoffing residual limb volume changes were assessed using an Omega tracer. After using the VAS socket, 0.8 percent increase in residual limb volume was observed after $10 \mathrm{~min}$ postdoffing compared with a 4.9 percent volume increase 
for the TSB suction socket. The two negative pressure settings showed similar results. However, the lower pressure setting produced a negative volume change that did not plateau after the 10 min measuring time. Furthermore, during the 3.5 mo of testing, a trend of decreased volume change was observed with the VAS socket. The participant stated that there was no need for residual limb volume management while using the VAS socket.

In a case series, Sanders et al. (DBS 13) examined the effect of a VAS socket on in-socket volume changes using bioimpedance [47]. They compared the results obtained with a TSB (non-VAS) socket and a TSB socket with pin lock system. Their results show that while using the VAS socket, the residual limb fluid increased during short-term walks in subjects not affected by any chronic diseases. However, the volume also increased while the vacuum was turned off or when a TSB socket with pin lock system was used for suspension. Two subjects who had chronic health complications (one with diabetes and the other with peripheral vascular disease) showed a decrease in limb volume after using elevated vacuum. However, the loss of limb fluid volume for the diabetic participant was less when using the VAS socket than when using the TSB socket with suction or pin lock. The authors also examined the effects of VAS socket on insocket volume changes when the vacuum was changed from low $(-25 \mathrm{kPa})$ to high $(-60 \mathrm{kPa})$. Results indicated that subjects showed an increase in limb volume with more elevated vacuum. Furthermore, the resistance of the limb tissue toward driving fluid out of the residual limb (i.e., volume decrease) was greater than driving fluid into the limb.

\section{Wound Healing: VAS}

Only two studies with weak evidence reported the effect of VAS sockets on residual limb wound healing $[26,35]$.

Weak evidence-In a case series reported by Hoskins et al. (DBS 13), four participants with open wounds on the residual limb were fitted with VAS sockets [26]. The vacuum level was selected based on participant preference and comfort $(-50.79 \mathrm{kPa}$ for three participants and $84.65 \mathrm{kPa}$ for one participant). The average time for wound closure was $161.50 \pm 29.44 \mathrm{~d}$ for an average wound size of $1.94 \pm 0.4 \mathrm{~cm}^{2}$. The authors stated that participants were able to ambulate with a VAS socket when also having a wound on the residual limb (1.55$2.41 \mathrm{~cm}^{2}$ ). The loss of vacuum, "improper use" of the prosthesis, and noncompliance with wound dressing protocols were stated by the authors as reasons for intermittent progress in wound healing. The authors claimed that the use of VAS sockets may increase the odds of maintaining a good socket fit by possibly decreasing the motion between the limb and socket, resulting in a decrease in mechanical forces and thus encouraging wound healing. Similar results were observed by Gerschutz et al. (DBS 13), where after 2 wk of VAS socket use in persons with diabetes, the wound decreased in size and changed colors; after 2 mo, it was completely closed; and after $3 \mathrm{mo}$, the coloration returned to normal [35]. The authors stated that similar wound sizes in diabetic patients usually take months to heal completely.

\section{Energy Cost of Walking: TSB}

One study with a moderate evidence level measured the energy cost of walking of users fitted with TSB sockets and different liners [28].

Moderate evidence-Brunelli et al. (DBS 22) reported that the percentage difference of the energy cost of walking between TSB sockets with Seal-In liner and TSB sockets with sleeve suspension was in favor of the Seal-In liner: 10 percent reduction in energy cost for floor walking, 12 percent for walking on a level treadmill, 20 percent for walking on the treadmill with a 12 percent incline, and 14.8 percent for walking on the treadmill with a 5 percent decline [28]. However, none of these differences reached significance.

\section{Muscle Activity}

Only one study with moderate evidence level evaluated prosthetic socket design and its influence on muscle activity [45]

PTB. Moderate evidence-Isakov et al. (DBS 16) reported that in participants wearing a prosthesis with a PTB socket and SACH foot, the ratio of electromyography (EMG) signals from biceps femoris/vastus medialis activities were larger on the prosthetic side than on the nonamputated side during the first half of stance phase [45]. However, during the second half of the stance phase and the entire swing phase, no significant differences were reported between prosthetic side and nonamputated limb for the EMG ratio of the biceps femoris/vastus medialis muscle signals. 


\section{Time and Cost of Socket Manufacturing}

Two studies measured the time and cost of socket manufacturing; one was scored as having robust evidence [24] and the other as having moderate evidence [22].

HS versus TSB. Robust evidence- - Results of a randomized controlled trial by Selles et al. (DBS 25) showed that manufacturing an HS Icex was significantly less time consuming than manufacturing a TSB socket (4.7 vs $11.3 \mathrm{~h}$ ) but the material costs were 1.5 times more expensive [24]. The number of postdelivery visits for the TSB socket group was significantly higher than for the HS socket group (4.42 vs 2.79).

HS versus PTB. Moderate evidence-Comparing HS Icex sockets with PTB sockets, Datta et al. (DBS 23) reported that the time for HS socket fabrication was 2.5 times shorter while the socket cost was 2.5 times higher than for PTB socket manufacturing [22]. Participants had fewer postdelivery revisits during 3 mo for adjustments of HS sockets than they had for PTB sockets, but the number of adjustments was not statistically significant.

\section{DISCUSSION}

Twenty-seven studies summarizing the scientific work of 15 years were reviewed in terms of the effects of transtibial socket designs on various quantitative-related outcomes.

The findings of the review suggest that gait symmetry is influenced by prosthetic socket design, in particular by socket suspension. In a PTB socket, a sleeve suspension or an SC wedge can result in improved gait symmetry [51]. Gait symmetry can be improved further when users are fitted with a TSB socket [43], and the best gait symmetry was reported with VAS sockets [13]. HS sockets were not different from TSB or PTB sockets for the analyzed gait parameters. Interestingly, the type of suspension provided by the elastomeric liner (Seal-In vs sleeve suspension) and the liner material (urethane vs silicone) used in TSB sockets seemed to have no effect on gait parameters $[28,40]$ but a thicker liner could result in an increase in GRF in the prosthetic limb at early stance [33].

Generally, TSB sockets with elastomeric liners show reduced pistoning and thus improve suspension. Pistoning variability depends on the type of suspension system used in an elastomeric liner. Results with VAS sockets show the least pistoning and highest satisfaction with the suspension, followed by TSB sockets with Seal-In liners. Lower pistoning reduction than with Seal-In liners was observed by elastomeric sleeve suspensions [28] and the least pistoning reduction was reported by using pin lock liners $[29,32]$. Similar conclusions were made in a systematic review conducted on prosthetic suspension systems by Gholizadeh et al. [52]. However, what remains unclear is the effect of suspension systems on relative soft tissue displacement and tibia motion in relation to the prosthetic socket. Soft tissue displacement as well as tibia motion in relation to the socket could cause internal tissue shear stress and thus should be the focus of further research studies.

Robust evidence shows that the VAS socket resulted in increased step length and stance duration symmetry than TSB sockets. It is suggested that perhaps improved suspension, improved proprioception, and a more secure socket and residual limb coupling lead to these results [13-14]. Furthermore, VAS sockets seem to encourage wound healing. Results reveal that wound closures occurred while participants used these types of sockets despite the presence of wounds. In addition, VAS sockets have shown to manage residual limb volume loss over prolonged time periods [35]. Potential for wound healing and management of residual limb volume could be attributed to a smaller positive interface pressure during stance phase and a negative interface pressure during swing phase, which could draw fluid into the residual limb, especially in more conical-shaped residual limbs [14].

Two recent literature reviews evaluate evidence with regard to the effect of the VAS sockets. Based on their review, Kahle et al. reported that existing literature gives some evidence that VAS sockets can decrease pistoning and improve residual limb volume control and pressure distribution [53]. Sanders and Fatone also concluded that VAS sockets could improve the control of residual limb volume, especially in participants with a traumatic cause of amputation [5]. They pointed out that two factors had been neglected in the studies: (1) the effect of VAS sockets on participants with comorbidities and/or other causes of amputation than trauma and (2) the employment of in-socket, real-time residual limb volume measurement technique to further assess the effect of VAS sockets on volume control. These two factors were later considered in a case series study with somewhat promising results in favor of the VAS socket [47].

With respect to the VAS effect on wound healing and function, Kahle et al. concluded that limited evidence 
exists to show that this socket can increase wound healing [53]. This conclusion differs from that obtained in the current review. The dissimilarity could be due to the different population recruited in the studies included for review. We included studies that investigated persons with a mature residual limb (i.e., $>6$ mo of prosthesis experience), while Kahle et al. included studies that analyzed persons in relation to postamputation residual limb volume management. In addition, Kahle et al. reported that limited evidence exists on the VAS socket's effect on "function." However, the three studies Kahle et al. included to analyze function used different definitions for this term, showed different methods, had different populations, and applied various outcome measures. Given the inconclusive evidence on VAS sockets and their effect on various related outcomes, further research would be welcome investigating VAS sockets in comparison with other socket designs on different populations with welldefined characteristics.

The current review also revealed that variability exists in interface pressure measurements between various studies, perhaps because of differences in prosthetic componentry, prosthetic alignment, pressure measurement equipment, and position of sensors [33]. Nevertheless, trends indicate that TSB sockets result in fewer pressure problems than PTB sockets [17]. In a PTB socket, the popliteal area experiences the highest pressure, followed by the patellar tendon and the anterior distal tibia region. In a TSB socket, however, the pressure distribution depends on the liner used: pin lock liners show a so-called "milking effect" with high positive pressures occurring at the proximal region of the residual limb and negative pressure occurring at the distal area of the residual limb. This possibly causes the fluids to draw into the limb with each step taken $[27,30,41]$. The high pressure area for Seal-In liners seems to be typically over the middle part of the residual limb due to the five seals around the outer surface of the liner [30]. The thickness of the liner could be effective in reducing interface pressure over bony prominences, as shown by Boutwell et al. [33]. Apart from accuracy and repeatability of the pressure measurement tools and related procedures, the main challenge with the studies on interface pressure measurement is the lack of knowledge about the pressure levels for an ideal socket fit. Although studies have been conducted to measure residual limb load tolerance thresholds on limited regions of the residual limb, more research is required in this area [54-55]. For example, exploring extensive residual limb load thresholds under dynamic and static situations would allow for the development of accurate pressure maps, perhaps revealing patterns across different socket designs and liners in relation to various ADLs. Previous reviews highlighted that there is a lack of research to help the understanding of socket residual limb biomechanical interactions, which documents residual limb soft tissue pressure tolerance and discomfort thresholds and relates this information to age, sex, and pathologies [56-57]. Over a decade has passed since these conclusions have been published, yet the lack of knowledge and understanding of these fundamental factors continues. However, knowing these factors is of primary importance for improving socket designs, particularly when new materials and components are regularly introduced to and used in the field. Knowing soft tissue pressure tolerance and discomfort thresholds would also have a beneficial effect on the rigor of scientific socket comparisons.

Interface pressure results related to Icecast HS sockets show less variability and thus are considered to be more consistent than corresponding results from PTB sockets. However, Icecast HS sockets seem to produce higher pressure-related results than PTB sockets, occurring mainly over the proximal residual limb. Nevertheless, it is suggested that Icecast HS sockets could reduce shear stress due to the smaller pressure gradients observed in the results [36]. The shape-capturing process for an Icex HS socket is thought to be more objective and thus repeatable than manual shape capturing, but studies on HS sockets are relatively scarce and more research is required to validate this concept. In addition, studies reported higher manufacturing costs associated with HS sockets but a shorter manufacturing time than PTB and TSB socket manufacturing. These results need to be interpreted with care because long-term cost-benefit ratios were not taken into account. For policy making and prosthetic service management, it would be useful to compare the cost of prosthetic services with related outcome measures through health economic investigations. Research in this area is therefore also recommended.

The majority of studies have applied more than one outcome measure to compare different socket designs. Nevertheless, the results are often inconsistent, and clear information about the relationship between cause and effect is difficult to obtain. In addition, note that a statistically significant result may not necessarily translate into a clinically meaningful socket fit and vice versa. Therefore, 
the challenge that remains is twofold: (1) addressing the lack of understanding of what constitutes a clinical ideal socket fit, and resulting thereof (2) addressing the methodical challenges. For example, addressing the lack of standards to measure the effect of a particular socket design on various levels: personal (e.g., comfort and pain), social (e.g., participation in ADLs), and cultural (e.g., integration into society). A socket has to provide a stable connection between the prosthesis and the residual limb via intermittent compliant soft tissue without jeopardizing comfort. These two factors, i.e., stability and comfort, can be explored multidimensionally by several variables such as interface normal and shear stress, socket-residual limb movement, volume and shape adaptability of the socket, residual limb blood supply, and pain. Because of the many evaluation possibilities these variables create, one has to first quantify clinically meaningful thresholds, perhaps based on participant perception of "good" and "bad" socket fit conditions. Next, use this information to fine-tune or further develop biomechanical and/or patient-reported outcome measures to quantify inter- and intrasocket fit differences for testing of current or future socket concepts. Such a systematic approach seems to be the most challenging process for future socket fit measurement studies.

\section{CONCLUSIONS}

The included studies have low to moderate methodological rigor. Most studies were conducted on PTB and TSB sockets, with only a few studies conducted on VAS and HS socket designs. The VAS socket had the best suspension of all reported socket designs, followed by a TSB suction socket, a TSB socket with sleeve suspension, and a TSB socket with pin lock liner. The least suspension is provided by a PTB socket with sleeve suspension or a PTB socket with SC design. Based on the few studies available for VAS sockets, the results seem to indicate that they improve gait symmetry, control residual limb volume fluctuations, and seem to affect residual limb health positively compared with other socket designs. The HS socket, however, has not been shown to be different from a PTB or TSB socket when analyzing biomechanical outcomes in older users. But the HS design seems to have the potential to create a more consistent socket fit, a variable that greatly influences the successful outcome of prosthetic fitting.
Using a systematic approach, future research should also focus on understanding the effect of socket fit alteration on related biomechanical or patient-reported outcome measures. Determining safe and comfortable pressure tolerant threshold(s) during various activities would further assist in clarifying comfort and related satisfaction results.

\section{ACKNOWLEDGMENTS}

\section{Author Contributions:}

Study concept and design: M. R. Safari, M. R. Meier.

Acquisition of data: M. R. Safari, M. R. Meier.

Analysis and interpretation of data: M. R. Safari, M. R. Meier. Critical revision of manuscript for important intellectual content:

M. R. Safari, M. R. Meier.

Financial Disclosures: The authors have declared that no competing interests exist.

Funding/Support: This material was unfunded at the time of manuscript preparation.

\section{REFERENCES}

1. Legro MW, Reiber G, del Aguila M, Ajax MJ, Boone DA, Larsen JA, Smith DG, Sangeorzan B. Issues of importance reported by persons with lower limb amputations and prostheses. J Rehabil Res Dev. 1999;36(3):155-63. [PMID:10659798]

2. Klute GK, Kantor C, Darrouzet C, Wild H, Wilkinson S, Iveljic S, Creasey G. Lower-limb amputee needs assessment using multistakeholder focus-group approach. J Rehabil Res Dev. 2009;46(3):293-304. [PMID:19675983] http://dx.doi.org/10.1682/JRRD.2008.02.0031

3. Klasson B, Buis A. Prosthetic socket fit: Implication of basic engineering principles. In: Simpson D, editor. Advanced prosthetic science, manual 3. Glasgow (United Kingdom): National Centre for Prosthetics and Orthotics, University of Strathclyde; 2006.

4. Dillingham TR, Pezzin LE, MacKenzie EJ, Burgess AR. Use and satisfaction with prosthetic devices among persons with trauma-related amputations: A long-term outcome study. Am J Phys Med Rehabil. 2001;80(8):563-71.

[PMID:11475475]

http://dx.doi.org/10.1097/00002060-200108000-00003

5. Sanders JE, Fatone S. Residual limb volume change: Systematic review of measurement and management. J Rehabil Res Dev. 2011;48(8):949-86. [PMID:22068373] http://dx.doi.org/10.1682/JRRD.2010.09.0189

6. Sanders JE, Zachariah SG, Jacobsen AK, Fergason JR. Changes in interface pressures and shear stresses over time 
on trans-tibial amputee subjects ambulating with prosthetic limbs: Comparison of diurnal and six-month differences. J Biomech. 2005;38(8):1566-73. [PMID:15958212] http://dx.doi.org/10.1016/j.jbiomech.2004.08.008

7. Hoaglund FT, Jergesen HE, Wilson L, Lamoreux LW, Roberts R. Evaluation of problems and needs of veteran lowerlimb amputees in the San Francisco Bay Area during the period 1977-1980. J Rehabil Res Dev. 1983;20(1):57-71. [PMID:6887067]

8. Hagberg K, Brånemark R, Hägg O. Questionnaire for Persons with a Transfemoral Amputation (Q-TFA): Initial validity and reliability of a new outcome measure. J Rehabil Res Dev. 2004;41(5):695-706. [PMID:15558399] http://dx.doi.org/10.1682/JRRD.2003.11.0167

9. Radcliffe CW. The biomechanics of below-knee prostheses in normal, level, bipedal walking. Artif Limbs. 1962;6(2): 16-24. [PMID:13972953]

10. Staats TB, Lundt J. The UCLA total surface bearing suction below-knee prosthesis. Clin Prosthet Orthot. 1987;11(3):118-30.

11. Kristinsson O. The ICEROSS concept: A discussion of a philosophy. Prosthet Orthot Int. 1993;17(1):49-55.

[PMID:8337100]

http://dx.doi.org/10.3109/03093649309164354

12. Patterson S. Editorial: Experiences with negative-pressure socket design [Internet]. The Academy Today. Washington (DC): American Academy of Orthotists \& Prosthetists; 2007. Available from: http://www.oandp.org/

AcademyTODAY/2007Jun/3.asp

13. Board WJ, Street GM, Caspers C. A comparison of transtibial amputee suction and vacuum socket conditions. Prosthet Orthot Int. 2001;25(3):202-9. [PMID:11860094] http://dx.doi.org/10.1080/03093640108726603

14. Beil TL, Street GM, Covey SJ. Interface pressures during ambulation using suction and vacuum-assisted prosthetic sockets. J Rehabil Res Dev. 2002;39(6):693-700. [PMID:17943671]

15. Street GM. Vacuum suspension and its effects on the limb. Orthopädie-Technik Quarterly, English Edition. 2006;4.

16. Brunelli S, Averna T, Delusso M, Traballesi M. Vacuum assisted socket system in transtibial amputees: Clinical report. Orthopädie-Technik Quarterly, English Edition. 2009;2.

17. Cluitmans J, Geboers M, Deckers J, Rings F. Experiences with respect to the ICEROSS system for trans-tibial prostheses. Prosthet Orthot Int. 1994;18(2):78-83. [PMID:7991364]

18. Datta D, Vaidya SK, Howitt J, Gopalan L. Outcome of fitting an ICEROSS prosthesis: Views of trans-tibial amputees. Prosthet Orthot Int. 1996;20(2):111-15.

[PMID:8876004]
19. Dasgupta AK, McCluskie PJ, Patel VS, Robins L. The performance of the ICEROSS prostheses amongst transtibial amputees with a special reference to the workplace- a preliminary study. Icelandic Roll on Silicone Socket. Occup Med (Lond). 1997;47(4):228-36. [PMID:9231496] http://dx.doi.org/10.1093/occmed/47.4.228

20. McCurdie I, Hanspal R, Nieveen R. ICEROSS - a consensus view: A questionnaire survey of the use of ICEROSS in the United Kingdom. Prosthet Orthot Int. 1997;21(2):124 28. [PMID:9285956]

21. Klute GK, Berge JS, Biggs W, Pongnumkul S, Popovic Z, Curless B. Vacuum-assisted socket suspension compared with pin suspension for lower extremity amputees: Effect on fit, activity, and limb volume. Arch Phys Med Rehabil. 2011;92(10):1570-75. [PMID:21963124] http://dx.doi.org/10.1016/j.apmr.2011.05.019

22. Datta D, Harris I, Heller B, Howitt J, Martin R. Gait, cost and time implications for changing from PTB to ICEX sockets. Prosthet Orthot Int. 2004;28(2):115-20.

[PMID:15382805]

http://dx.doi.org/10.1080/03093640408726696

23. Hachisuka K, Nakamura T, Ohmine S, Shitama H, Shinkoda K. Hygiene problems of residual limb and silicone liners in transtibial amputees wearing the total surface bearing socket. Arch Phys Med Rehabil. 2001;82(9):128690. [PMID:11552206] http://dx.doi.org/10.1053/apmr.2001.25154

24. Selles RW, Janssens PJ, Jongenengel CD, Bussmann JB. A randomized controlled trial comparing functional outcome and cost efficiency of a total surface-bearing socket versus a conventional patellar tendon-bearing socket in transtibial amputees. Arch Phys Med Rehabil. 2005;86(1):154-61, quiz 180. [PMID:15641007]

http://dx.doi.org/10.1016/j.apmr.2004.03.036

25. Liberati A, Altman DG, Tetzlaff J, Mulrow C, Gøtzsche PC, Ioannidis JP, Clarke M, Devereaux PJ, Kleijnen J, Moher D. The PRISMA statement for reporting systematic reviews and meta-analyses of studies that evaluate health care interventions: Explanation and elaboration. Ann Intern Med. 2009;151(4):W65-94. [PMID:19622512] http://dx.doi.org/10.7326/0003-4819-151-4-200908180-00136

26. Hoskins RD, Sutton EE, Kinor D, Schaeffer JM, Fatone S. Using vacuum-assisted suspension to manage residual limb wounds in persons with transtibial amputation: A case series. Prosthet Orthot Int. 2014;38(1):68-74.

[PMID:23685916] http://dx.doi.org/10.1177/0309364613487547

27. Eshraghi A, Abu Osman NA, Gholizadeh H, Ali S, Sævarsson SK, Wan Abas WA. An experimental study of the interface pressure profile during level walking of a new suspension system for lower limb amputees. Clin Biomech 
(Bristol, Avon). 2013;28(1):55-60. [PMID:23157843]

http://dx.doi.org/10.1016/j.clinbiomech.2012.10.002

28. Brunelli S, Delussu AS, Paradisi F, Pellegrini R, Traballesi M. A comparison between the suction suspension system and the hypobaric Iceross Seal-In ${ }^{\circledR}$ X5 in transtibial amputees. Prosthet Orthot Int. 2013;37(6):436-44.

[PMID:23436696]

http://dx.doi.org/10.1177/0309364613476531

29. Eshraghi A, Abu Osman NA, Karimi MT, Gholizadeh H, Ali S, Wan Abas WA. Quantitative and qualitative comparison of a new prosthetic suspension system with two existing suspension systems for lower limb amputees. Am J Phys Med Rehabil. 2012;91(12):1028-38.

[PMID:23168378]

http://dx.doi.org/10.1097/PHM.0b013e318269d82a

30. Ali S, Osman NA, Mortaza N, Eshraghi A, Gholizadeh H, Wan Abas WA. Clinical investigation of the interface pressure in the trans-tibial socket with Dermo and Seal-In X5 liner during walking and their effect on patient satisfaction. Clin Biomech (Bristol, Avon). 2012;27(9):943-48.

[PMID:22795863]

http://dx.doi.org/10.1016/j.clinbiomech.2012.06.004

31. Gholizadeh H, Osman NA, Kamyab M, Eshraghi A, Abas WA, Azam MN. Transtibial prosthetic socket pistoning: Static evaluation of Seal-In(®) X5 and Dermo(®) Liner using motion analysis system. Clin Biomech (Bristol, Avon). 2012;27(1):34-39. [PMID:21794965] http://dx.doi.org/10.1016/j.clinbiomech.2011.07.004

32. Gholizadeh H, Abu Osman NA, Eshraghi A, Ali S, Sævarsson SK, Wan Abas WA, Pirouzi GH. Transtibial prosthetic suspension: Less pistoning versus easy donning and doffing. J Rehabil Res Dev. 2012;49(9):1321-30.

[PMID:23408214]

http://dx.doi.org/10.1682/JRRD.2011.11.0221

33. Boutwell E, Stine R, Hansen A, Tucker K, Gard S. Effect of prosthetic gel liner thickness on gait biomechanics and pressure distribution within the transtibial socket. J Rehabil Res Dev. 2012;49(2):227-40. [PMID:22773525] http://dx.doi.org/10.1682/JRRD.2010.06.0121

34. Gholizadeh H, Abu Osman NA, Kamyab M, Eshraghi A, Lúvíksdóttir AG, Wan Abas WA. Clinical evaluation of two prosthetic suspension systems in a bilateral transtibial amputee. Am J Phys Med Rehabil. 2012;91(10):894-98. [PMID:22173083] http://dx.doi.org/10.1097/PHM.0b013e31823c74d7

35. Gerschutz MJ, Denune JA, Colvin JM, Schober GC. Elevated vacuum suspension influence on lower limb amputee's residual limb volume at different vacuum pressure settings. J Prosthet Orthot. 2010;22(4):252-56. http://dx.doi.org/10.1097/JPO.0b013e3181f903df

36. Dumbleton T, Buis AW, McFadyen A, McHugh BF, McKay G, Murray KD, Sexton S. Dynamic interface pres- sure distributions of two transtibial prosthetic socket concepts. J Rehabil Res Dev. 2009;46(3):405-15.

[PMID:19675992]

http://dx.doi.org/10.1682/JRRD.2008.01.0015

37. Lenka PK, Ratnesh K, Tibarewala DN. Gait measures and dynamic weight bearing in young and elder trans-tibal amputee using PTB prosthesis with SACH foot. Al Ameen J Med Sci. 2008;1(2):115-25.

38. Rogers BM, Bosker GM, Faustini MP, Walden GM, Neptune RR, Crawford RP. Case report: Variably compliant transtibial prosthetic socket fabricated using solid freeform fabrication. J Prosthet Orthot. 2008;20(1):1-7. http://dx.doi.org/10.1097/JPO.0b013e31815ea839

39. Dou P, Jia X, Suo S, Wang R, Zhang M. Pressure distribution at the stump/socket interface in transtibial amputees during walking on stairs, slope and non-flat road. Clin Biomech (Bristol, Avon). 2006;21(10):1067-73.

[PMID:16919376]

http://dx.doi.org/10.1016/j.clinbiomech.2006.06.004

40. Aström I, Stenström A. Effect on gait and socket comfort in unilateral trans-tibial amputees after exchange to a polyurethane concept. Prosthet Orthot Int. 2004;28(1):28-36. [PMID:15171575]

41. Beil TL, Street GM. Comparison of interface pressures with pin and suction suspension systems. J Rehabil Res Dev. 2004;41(6A):821-28. [PMID:15685470]

42. Goswami J, Lynn R, Street G, Harlander M. Walking in a vacuum-assisted socket shifts the stump fluid balance. Prosthet Orthot Int. 2003;27(2):107-13. [PMID:14571940] http://dx.doi.org/10.1080/03093640308726666

43. Yiğiter K, Sener G, Bayar K. Comparison of the effects of patellar tendon bearing and total surface bearing sockets on prosthetic fitting and rehabilitation. Prosthet Orthot Int. 2002;26(3):206-12. [PMID:12562067] http://dx.doi.org/10.1080/03093640208726649

44. Tanner JE, Berke GM. Radiographic comparison of vertical tibial translation using two types of suspensions on a transtibial prosthesis: A case study. J Prosthet Orthot. 2001; 13(1):14-16. http://dx.doi.org/10.1097/00008526-200103000-00012

45. Isakov E, Keren O, Benjuya N. Trans-tibial amputee gait: Time-distance parameters and EMG activity. Prosthet Orthot Int. 2000;24(3):216-20. [PMID:11195356] http://dx.doi.org/10.1080/03093640008726550

46. Zhang M, Turner-Smith AR, Tanner A, Roberts VC. Clinical investigation of the pressure and shear stress on the trans-tibial stump with a prosthesis. Med Eng Phys. 1998;20(3):188-98. [PMID:9690489] http://dx.doi.org/10.1016/S1350-4533(98)00013-7

47. Sanders JE, Harrison DS, Myers TR, Allyn KJ. Effects of elevated vacuum on in-socket residual limb fluid volume: Case study results using bioimpedance analysis. J Rehabil 
Res Dev. 2011;48(10):1231-48. [PMID:22234667]

http://dx.doi.org/10.1682/JRRD.2010.11.0219

48. Coleman KL, Boone DA, Laing LS, Mathews DE, Smith DG. Quantification of prosthetic outcomes: Elastomeric gel liner with locking pin suspension versus polyethylene foam liner with neoprene sleeve suspension. J Rehabil Res Dev. 2004;41(4):591-602. [PMID:15558387] http://dx.doi.org/10.1682/JRRD.2004.04.0591

49. Hachisuka K, Dozono K, Ogata H, Ohmine S, Shitama H, Shinkoda K. Total surface bearing below-knee prosthesis: Advantages, disadvantages, and clinical implications. Arch Phys Med Rehabil. 1998;79(7):783-89. [PMID:9685091] http://dx.doi.org/10.1016/S0003-9993(98)90356-2

50. Ali S, Abu Osman NA, Naqshbandi MM, Eshraghi A, Kamyab M, Gholizadeh H. Qualitative study of prosthetic suspension systems on transtibial amputees' satisfaction and perceived problems with their prosthetic devices. Arch Phys Med Rehabil. 2012;93(11):1919-23.

\section{[PMID:22579945]}

http://dx.doi.org/10.1016/j.apmr.2012.04.024

51. Wirta RW, Golbranson FL, Mason R, Calvo K. Analysis of below-knee suspension systems: Effect on gait. J Rehabil Res Dev. 1990;27(4):385-96. [PMID:2089149] http://dx.doi.org/10.1682/JRRD.1990.10.0385

52. Gholizadeh H, Abu Osman NA, Eshraghi A, Ali S, Razak NA. Transtibial prosthesis suspension systems: Systematic review of literature. Clin Biomech (Bristol, Avon). 2014; 29(1):87-97. [PMID:24315710] http://dx.doi.org/10.1016/j.clinbiomech.2013.10.013

53. Kahle JT, Orriola JJ, Johnston W, Highsmith MJ. The effects of vacuum-assisted suspension on residual limb physiology, wound healing, and function: A systematic review. Technol Innov. 2014;15(4):333-41. http://dx.doi.org/10.3727/194982413X13844488879177

54. Lee WC, Zhang M, Mak AF. Regional differences in pain threshold and tolerance of the transtibial residual limb:
Including the effects of age and interface material. Arch Phys Med Rehabil. 2005;86(4):641-49. [PMID:15827912] http://dx.doi.org/10.1016/j.apmr.2004.08.005

55. Zhang M, Lee WC. Quantifying the regional load-bearing ability of trans-tibial stumps. Prosthet Orthot Int. 2006;30(1):25-34. [PMID:16739779] http://dx.doi.org/10.1080/03093640500468074

56. Sewell P, Noroozi S, Vinney J, Andrews S. Developments in the trans-tibial prosthetic socket fitting process: A review of past and present research. Prosthet Orthot Int. 2000;24(2):97-107. [PMID:11061196] http://dx.doi.org/10.1080/03093640008726532

57. Mak AF, Zhang M, Boone DA. State-of-the-art research in lower-limb prosthetic biomechanics-socket interface: A review. J Rehabil Res Dev. 2001;38(2):161-74.

[PMID:11392649]

Submitted for publication August 13, 2014. Accepted in revised form April 14, 2015.

This article and any supplementary material should be cited as follows:

Safari MR, Meier MR. Systematic review of effects of current transtibial prosthetic socket designs-Part 2: Quantitative outcomes. J Rehabil Res Dev. 2015;52(5): 509-26.

http://dx.doi.org/10.1682/JRRD.2014.08.0184

ResearcherID: Mohammad Reza Safari, PhD: I-55322014; Margrit Regula Meier, PhD: I-5388-2015

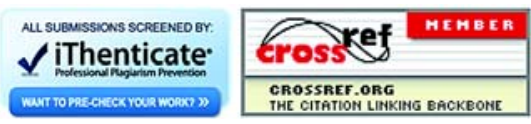

